\title{
ALMACENAMIENTOS, VOLATILIDAD \\ DE LOS PRECIOS DE LOS GRANOS \\ Y DISTRIBUCION DE LA RENTA: \\ COMENTARIOS A LA REPLICA \\ DE BARTOLOME YUN
}

ENRIQUE LLOPIS AGELAN

Universidad Complutense de Madrid

En relación a la reseña que publiqué en esta misma Revista sobre su libro ', Bartolomé Yun ha señalado que contiene inexactitudes, omite aspectos fundamentales, no recoge el «nuevo modelo explicativo general del desarrollo y crisis del Antiguo Régimen» que la obra encierra, no incardina el trabajo dentro de la controversia internacional acerca de la transición del feudalismo al capitalismo, peca de "puntillismo» y busca de modo artificial la polémica ${ }^{2}$.

Para la inmensa mayoría de lectores no tendría ningún interés que ocupara mi espacio contestando de forma pormenorizada a cada uno de los puntos de la réplica de Bartolomé Yun; además, la lectura de su libro, que vuelvo a recomendar de manera encarecida, y de mi reseña constituye el modo óptimo para que los interesados, en el caso de que hubiera alguno, juzguen hasta qué punto están justificadas las «quejas» de Bartolomé Yun. Por ello, sólo me permitiré unos breves comentarios antes de centrarme en la existencia o inexistencia de base para la polémica.

En el primer párrafo de mi reseña se subrayan la atención previa y prioritaria dedicada por el autor a la distribución del producto y el innovador estudio que en la obra se efectúa de las interrelaciones entre el desarrollo del Estado absolutista y la evolución económica y social. Ello, junto a otras consideraciones de mi resumen, permite, a mi juicio, dar a conocer el planteamiento general del libro y sugerir de modo implícito la posición del mismo dentro de las controversias internacionales más recientes sobre la transición del feudalismo al capitalismo. $\mathrm{El}$ «debate Brenner» tiene un indudable interés, pero éste procede bastante más de la revitalización de la polémica acerca de las interrelaciones economía-política y producción-distribución que de las síntesis macrohistóricas realizadas por los distintos participantes en aquél. Estas últimas difícilmente pueden librarse del reduccionismo, defecto en el que no ha incurrido el libro de Bartolomé Yun. La no incardinación explícita de aquél en el «debate Brenner" no me parece que. merme en un ápice su

' Revista de Historia EconómicA, año VI, núm. 3 (otoño 1988), pp. 744.752.

'Bartolomé Yun (1989), pp. 461-477. 
valor añadido neto. Convendría recordar que antes de la irrupción de la referida controversia se publicaron numerosos libros, también en nuestro país - por ejemplo, los de Josep Fontana-, que combatían de modo implícito o explícito el «modelo mercantil» y las interpretaciones de «corte malthusiano". No me parece, por tanto, que el «debate Brenner» constituya un punto de referencia absolutamente inexcusable a la hora de examinar las investigaciones sobre la economia y la sociedad de la Europa moderna.

Expresé mi deseo de que el libro de Bartolomé Yun suscitara alguna polémica, entre otras razones porque ello contribuiría a potenciar su impacto dentro y fuera de nuestras fronteras. No se han producido las respuestas que esperaba. ¿Toda la responsabilidad debe ser atribuida a la tradición firmemente arraigada entre los historiadores españoles de no provocar controversias? El peso de esa costumbre es indudable, pero me pregunto si la forma en que Bartolomé Yun presentó los resultados de su investigación no ha contribuido a dificultar el debate y un uso más intensivo de aquéllos. Las 650 densas páginas, algunas nada fáciles, no son, desde luego, el mejor reclamo para la amplia difusión de la obra. Aunque no pretendo ni retractarme ni relativizar «mi» lectura de libro, confieso que su síntesis me ocupó un elevado número de horas, que hube de renunciar a mencionar todas sus aportaciones relevantes y que no me atreví a ofrecer en pocas palabras el «nuevo modelo explicativo general del desarrollo y crisis del Antiguo Régimen».

Mi reseña en absoluto pretendía abrir una polémica. Si me hubiese fijado ese objetivo, habría escrito una larga nota: sólo un irresponsable puede aspirar a exponer y defender sus posiciones frente a un libro de esta envergadura en tres páginas. Mi auténtico propósito era el de estimular la lectura de una excelente obra que consideraba - -y sigo considerando- susceptible de generar un provechoso debate. Ahora bien, ello no fue óbice para que incumpliese unas de las obligaciones de todo reseñador: la crítica -aunque ésta pueda ser tildada a veces de «puntillosa»-

Caso de haberme planteado polemizar, mis «dudas y discrepancias» se habrían centrado principalmente en temas que considero importantes para entender el desarrollo general del Antiguo Régimen en Castilla y que no reciben suficiente o adecuada atención en «Sobrẹ la transición al capitalismo en Castilla». Por ejemplo, la ampliación y afianzamiento de los derechos de propiedad territorial de sectores de la nobleza en los siglos xvi y xvII, la variedad de estructura de ingresos de las distintas economías señoriales —on las consiguientes secuelas cara a sus estrategias políticas y económicas-, los grandes intereses pecuarios de ciertos grupos de privilegiados y las interrelaciones entre la evolución urbana y la rural. A la postre, quien pretenda juzgar el último libro de Bartolomé Yun habrá de enfrentarse al dilema de 
considerarlo fundamentalmente una monografía, o, por el contrario, un intento de reinterpretar el desarrollo económico y político de la Castilla moderna.

Esta tampoco es la ocasión para polemizar con Bartolomé Yun acerca de los puntos reseñados en el párrafo anterior, pero sí considero inexcusable plantear mi disconformidad con algunas de las afirmaciones de su réplica.

A Bartolomé Yun le ha sorprendido mi «apasionamiento» por los almacenamientos «especulativos» de granos. El motivo de tal preocupación es bien simple: la volatilidad de los precios de los cereales panificables afectaba a la distribución de la renta y aquélla era tanto mayor cuanto menor fuera el volumen relativo de sloks ${ }^{3}$. Sabemos que las cosechas de granos registraban bruscas oscilaciones - aunque convendría medirlas y averiguar si se produjo algún cambio significativo en el transcurso de la Edad Moderna- y que la demanda de los mismos era bastante rígida - aunque no totalmente inelástica como a veces se supone-. Además, la mayoría de pequeños oferentes se veían obligados a vender sus excedentes tras la siega a fin de poder hacer frente a diversos pagos en metálico. Por consiguiente, la intensidad de las variaciones estacionales e interanuales de los precios dependía esencialmente de los cambios en los flujos de granos remitidos a los mercados y aquéllos tenían una estrecha relación con el tamaño relativo de las partes de las cosechas que se ensilaban con el propósito de venderlas en los meses «mayores" o en los años agrícolas siguientes. Lógicamente, la posterior gestión de los almacenamientos también influía en la distribución temporal de las ventas. En definitiva, la reducción de la volatilidad del precio del trigo exigía un incremento del volumen relativo de almacenamientos. Como la capacidad operativa de los pósitos era limitada ${ }^{4}$, puede afirmarse que la cuantía de los stocks privados tenía que afectar de manera importante a la intensidad de las fluctuaciones de los precios de los cereales panificables.

Todos estamos convencidos de que los mercados trigueros de la Castilla moderna estuvieron dominados por un número relativamente reducido de grandes oferentes - rentistas, perceptores de diezmos, hacendados locales y arrendadores de rentas y derechos-, pero convendría no olvidar que su capacidad para aprovechar las diferencias temporales y espaciales de los precios se basaba en la insuficiente dimensión de los almacenamientos «especulativos».

Estoy completamente de acuerdo con Bartlomé Yun cuando afirma que el incremento en la intensidad de las fluctuaciones de los precios del trigo provocaba un empeoramiento del nivel de vida de la mayor parte de familias terracampinas - también, probablemente, de las castellanas-. Tendremos en el futuro que intentar precisar el impacto de la volatilidad de los precios

${ }^{3}$ Defino el volumen relativo de stocks como la ratio entre almacenamientos y consumo - producción anual.

4oncepción de Castro (1987), pp. 104-108. 
sobre la distribución del ingreso, aunque es obvio que las fuertes oscilaciones estacionales e interanuales perjudicaban a todos los consumidores sin recursos para financiar el mantenimiento de reservas y a los pequeños productores, cuyo porcentaje era bastante elevado en Tierra de Campos y en numerosas zonas de Castilla, que solían ser oferentes en años de buenas o aceptables cosechas y demandantes en los restantes ${ }^{5}$. Sin embargo, no me parece válida ni significativa la estimación efectuada por Bartolomé Yun para comparar la volatilidad de las cotizaciones del trigo antes y después de $1765^{\circ}$. Ello lo ha abordado empleando la serie de precios medios decenales montados de Segovia ${ }^{7}$. Aunque se trate de un cálculo preliminar y grosero, como el propio Yun señala, tal estimación exige el uso, cuando menos, de precios medios anuales.

José Luis Escrivá y quien suscribe modelizamos las series de precios medios anuales del trigo vendido por el cabildo de la catedral de Zamora y por los monasterios cistercienses de Sandoval (León) y Rioseco (Burgos). Los modelos univariantes, identificados, estimados y validados de acuerdo con la metodología de Box y Jenkins ${ }^{8}$, proporcionan, según los expertos en series temporales ${ }^{9}$, un excelente indicador para medir la volatilidad: la desviación típica del "ruido blanco». Los resultados obtenidos fueron los siguientes ${ }^{10}$ :

\begin{tabular}{|c|c|c|}
\hline & Período $1699-1764$ & Período 1765.1808 \\
\hline Mercado & $\begin{array}{l}\text { Desviación típica } \\
\text { del «ruido blanco» }\end{array}$ & $\begin{array}{l}\text { Desviación típica } \\
\text { del «ruido blanco» }\end{array}$ \\
\hline $\begin{array}{llllllll}\text { Zamora } & \ldots & \ldots & \ldots & \ldots & \ldots & \ldots & \\
\text { Zandoval } & \ldots & \ldots & \ldots & \ldots & \ldots & \ldots \\
\text { Sandoseco } & \ldots & \ldots & \ldots & \ldots & \ldots & \ldots & \ldots \\
\text { Riose } & \ldots & \ldots & \ldots & \ldots & \ldots & \ldots & \ldots\end{array}$ & $\begin{array}{l}0,328 \\
0,260 \\
0,240\end{array}$ & $\begin{array}{l}0,236 \\
0,341 \\
0,234\end{array}$ \\
\hline
\end{tabular}

El comportamiento de la desviación típica del «ruido blanco» de los tres modelos univariantes estimados no avala la tesis de incremento de la vola-

${ }^{5}$ Esta clase de estudios puede y debe tener uno de sus principales soportes en un tipo de aprovechamiento de los Libros de Hacienda del Catastro de la Ensenada similar al efectuado por Bartolomé Yun (1987), pp. $474-480$ y cuadro 81 .

- Bartolomé Yun (1989), p. 466.

7 Publicada por Angel García Sanz (1977), p. 204.

${ }^{8}$ G. E. P. Box y G. M. Jenkins (1970).

- Agustín Maravall y Samuel Bentolila (1984).

10 José Luis Escrivá y Enrique Llopis (1987), p. 129. En este trabajo modelizamos más series de precios y estudiamos un período más amplio. Aquí sólo hemos recogido la información correspondiente a las fases objeto de polémica. 
tilidad del precio del trigo en el último tercio del siglo xvirr. Es cierto, no obstante, que tampoco corrobora lo contrario ${ }^{11}$. En el supuesto de que no se hubiesen producido cambios mínimamente apreciables en el funcionamiento del mercado de granos a raíz de las reformas de 1765 , cabría esperar que la abolición de la tasa y la agudización de las crisis frumentarias se hubieran traducido en un alza sensible de la volatibilidad del precio del trigo en las décadas postreras del Setecientos. Por tanto, el simple mantenimiento de aquélla, caso de confirmarse, sería por sí mismo revelador de la existencia de algún tipo de transformaciones en el funcionamiento de los mercados de granos.

Sigo considerando que «el desarrollo de una capa de campesinos acomodados y la parcial liberación del comercio de granos tuvieron que incrementar el número de "especuladores" y que reducir algo (el subrayado lo añado ahora) el grado de oligopolización de los mercados». Es cierto que el aumento de la renta de la tierra se tradujo en una distribución más desigual del pro: ducto en la segunda mitad del siglo xviri; también me parece oportuna la observación de Bartolomé Yun de que la resistencia al pago de diezmos y rentas hube de originar cambios trascendentales en el funcionamiento de los mercados durante la desarticulación del Antiguo Régimen. Ahora bien, el aludido incremento de detracciones no parece haber sido óbice para que los campesinos acomodados continuaran encumbrándose y acapararan buena parte de las tierras puestas a la venta en las desamortizaciones de la época de Godoy - y no sólo en la comarca estudiada por Yun-. Pero, sobre todo, quisiera subrayar la ruptura del statu quo que podía entrañar la incorporación de comerciantes profesionales al mercado de granos: 1) la entrada de nuevos y poderosos oferentes reducía la capacidad de maniobra de quienes habían venido disfrutando de un oligopolio que se había constituido al amparo de una legislación restrictiva y de la pervivencia de unas determinadas relaciones socioeconómicas; 2) los "advenedizos», dadas sus posibilidades de inversión, podían aumentar de manera importante los almacenamientos «especulativos» $y$, por ende, reducir la volatilidad de los precios y la rentabilidad del negocio; 3) los comerciantes profesionales iban a ser demandantes en periodos en los que los mercados estuviesen bien abastecidos y oferentes en los que escaseasen los alimentos, lo que mitigaría la intensidad de las fluctuaciones estacionales y cíclicas de los precios de los cereales. Fue, precisamente, la potencial

$"$ Del análisis de las correlaciones cruzadas de las «innovaciones" de las distintas series de precios parece inferirse que el proceso de integración de los mercados se estancó en los últimos decenios del siglo xvin y en los primeros años del xix. Ello pudo obedecer al recrudecimiento del intervencionismo cuando se agravaron los problemas de abastecimiento de las urbes, especialmente el de Madrid [José Luis Escrivá y Enrique Llopis (1987), pp. 126-127]. 
capacidad de la burguesía mercantil de romper el statu quo del negocio lo que obligó a quienes venían disfrutando del oligopolio a tratar de impedir que aquélla llegara a alcanzar posiciones destacadas en el comercio de granos. En este sentido, cabe interpretar la furibunda campaña lanzada contra la figura del mercader profesional a raíz de la adopción de las medidas liberalizadoras en 1765, y en la que tuvieron una destacada participación algunas autoridades de la Administración Central que parecen estar mucho más cerca de la órbita de los viejos poderes que de la del núcleo de gobernantes «ilustrados" ${ }^{12}$. También es probable que el desabastecimiento de 1765-66 fuera provocado en parte por los «viejos especuladores» con el propósito de socavar la tímida reforma.

A la postre, quienes venían beneficiándose del oligopolio, aprovechando, entre otros resortes, el control que ejercían sobre numerosos ayuntamientos de ciudades y villas, lograron desnaturalizar y frenar la reforma del comercio de granos: la burguesía urbana no pudo entrar a fondo en el «negocio» hasta el desmoronamiento del Antiguo Régimen ${ }^{13}$. Sin embargo, convendría que nuevas investigaciones aclarasen y precisasen diversas cuestiones: 1) la naturaleza, entidad, resultados y secuelas de los enfrentamientos entre los beneficiarios del viejo oligopolio y los grupos burgueses interesados en participar en la compra-venta de granos; 2) chasta qué punto la irrupción de comerciantes profesionales introdujo cambios en el funcionamiento de los mercados de cereales?; 3) ¿en qué medida el cierto desarrollo de la red mercantil del último tercio del siglo xvir contribuyó a que el hundimiento de los pósitos, en los primeros años del XIX, no llegara a provocar un colapso en el sistema de abasto de las ciudades?

En suma, aunque el volumen de cereales comprados y vendidos por los comerciantes profesionales no creciera de manera espectacular, las actividades de aquéllos generaban importantes alteraciones en el funcionamiento de los mercados, al tiempo que iban propiciando la aparición de fricciones entre los viejos grupos dominantes y determinado sector de la burguesía urbana que reclamaba su participación en un lucrativo negocio al amparo de las reformas adoptadas por los gobernantes «ilustrados».

Tampoco puedo compartir la tesis de Bartolomé Yun de que la alta rentabilidad del comercio de granos, junto a otros factores, contribuyó «a configurar e incluso a alentar un modelo de crecimiento económico que consagraría profundas insuficiencias en el aparato productivo y techos muy bajos con importantes estrangulamientos en el desarrollo industrial» ${ }^{14}$. Los rendi-

12 Gonzalo Anes (1970), pp. 344-347.

${ }^{13}$ Esta es una de las principales conclusiones del libro de Concepción de Castro (1987).

${ }^{14}$ Bartolomé Yun (1989), p. 463. 
mientos extraordinarios en el tráfico de cereales, según Yun, desalentaron las inversiones industriales y las mejoras agrarias. A mi juicio, si en el comercio de granos se obtenían beneficios tan elevados - y esto parece incuestionable habida cuenta del nivel de volatilidad de los precios- y todos ellos hubieran sido puntualmente reinvertidos en la adquisición de stocks, éstos habrían crecido a un ritmo trepidante $\mathrm{y}$, por consiguiente, la rentabilidad del negocio habría descendido de modo significativo ${ }^{15}$. La pervivencia de beneficios extraordinarios indica, entre otras cuestiones, el mantenimiento de fuertes barreras de entrada al comercio de granos - es decir, las dificultades que aún tenía la burguesía mercantil para introducirse a fondo en tales actividadesy la no reinversión en la compra de nuevos stocks de una elevada parte de aquéllos: muchas de las economías que venían aprovechándose del oligopolio, sobre todo las nobiliarias y las eclesiásticas, tenían un marcado carácter consuntivo y, por ende, escasa capacidad de ahorro e inversión ${ }^{16}$. En cuanto al comportamiento de los campesinos acomodados en una comarca en la que las posibilidades roturadoras eran limitadas y en la que el mercado de tierras fue bastante estrecho hasta las desamortizaciones de la época de Godoy, resulta lógico suponer, en un período en el que los precios relativos evolucionaban favorablemente a sus intereses, que tratasen de introducir mejoras en sus explotaciones ${ }^{17}$, salvo que estuviesen dispuestos y tuviesen capacidad para convertirse también en mercaderes profesionales de granos -es decir, en compradores y vendedores-, alternativa que no debía estar al alcance de la mayoría de aquéllos.

Bartolomé Yun señala que el incremento de las exportaciones de cereales de Tierra de Campos acabó traduciéndose en una creciente afluencia de manufacturas foráneas a los mercados comarcanos, lo que dificultó el desarrollo industrial de la zona ${ }^{18}$. Antes de aceptar esa interpretación deberíamos conocer las respuestas a los siguientes interrogantes: 1) ¿qué posibilidades de progreso y de competitividad a medio y largo plazo tenían las manufacturas de Tierra de Campos?; 2) ¿qué hubiera ocurrido con el precio del transporte y con la comercialización del grano de la comarca en el caso de inexistencia de los referidos retornos industriales? Todavía se puede añadir una observación más: algunos terracampinos se beneficiaron de las importa-

is Suponiendo que se reinvirtiesen todos los beneficios, que éstos ascendieran sólo al 15 por 100 y que los precios de los granos se incrementasen al 5 por 100 -en realidad fue bastante inferior-, los almacenamientos habrían crecido a una tasa anual superior al 9,5 por 100 . Es obvio que el comercio de granos no podía crecer a semejantes tasas en la Castilla del siglo Xvili.

${ }^{16}$ José Luis Escrivá y Enrique Llopis (1987), pp. 118-120.

17 Es cierto, no obstante, que la persistencia de la obligación de diezmar suponía un lastre importante para las inversiones agrarias.

${ }^{18}$ Bartolomé Yun (1989), p. 463. 
ciones de manufacturas foráneas, ya que éstas debían ser más baratas o de mejor calidad que las fabricadas en la zona.

Bartolomé Yun prefiere la expresión «economía de los terracampinos» a la de «economía de Tierra de Campos». El empleo de una u otra me parece irrelevante - los historiadores y economistas suelen utilizar la primera- siempre y cuando no se confunda crecimiento económico con bienestar social. Considero, pues, que se puede y debe plantear el efecto «neto» de la mayor conexión de los mercados cerealícolas sobre la economía terracampina. Para averiguar tal efecto «neto» empleamos, aunque no lo explicitemos, un contrafactual: ¿qué ventajas e inconvenientes habrían tenido las economías vecinales de la comarca en el supuesto de que no hubiera acontecido el avance en el proceso de integración de los mercados de granos en la Castilla del siglo xvin? En mi reseña no afirmé que la situación de las economías de los terracampinos mejorase de manera importante en la segunda mitad del sig!o xviII, sino que. el comportamiento de aquéllas, en conjunto, debió ser mejor del que previsiblemente habría resultado de no haberse producido la mayor interconexión entre los mercados cerealícolas.

Evaluar los efectos positivos y negativos del avance en el proceso de integración de los mercados exige contemplar las dos facetas de las economías familiares: la de consumidoras y la de productoras.

La excelente explotación de las Respuestas Particulares del Catastro de la Ensenada ha permitido a Bartolomé Yun, entre otras cuestiones, demostrar que más del 60 por 100 de la población de la comarca era demandante "neto» de granos ${ }^{19}$. Yun ha enfatizado los inconvenientes de la creciente conexión de los mercados para la mayor parte de los demandantes «netos» de cereales de Tierra de Campos, pero conviene no olvidar que dicho proceso de integración también hubo de tener algunas ventajas para aquéllos: por un lado, la intensificación de los flujos espaciales de mercancías tendía a reducir la volatilidad de los precios ${ }^{20}$; por otro, la dependencia con respecto a la cosecha del entorno se reducía, lo que mitigaba las escaseces en algunos de los años de cosechas catastróficas. Es cierto, no obstante, que las ventajas de la articulación de los mercados no eran las mismas para los consumidores de zonas excedentarias que para los de áreas deficitarias: como el nivel de precios era más reducido en las comarcas exportadoras y el coste del transporte bastante alto, aquéllas únicamente podían recibir flujos de granos cuando su mal año agrícola coincidía con uno bueno en la mayor parte de la región.

19 Bartolomé Yun (1989), p. 465.

${ }^{20}$ Los cereales almacenados eran conducidos allí donde los precios uran más altos. 
A nivel macroeconómico, difícilmente puede cuestionarse que el aumento de las exportaciones de cereales tuviese un reflejo positivo en la renta, la producción agraria y el empleo comarcal. La revalorización de los granos y el aumento de la renta tuvieron, como ha expresado Yun, efectos diferentes en los distintos tipos de explotaciones agrarias. Es cierto que numerosas economías campesinas, habida cuenta de sus reducidas capacidades productivas, de las necesidades familiares de consumo y de la cuantía de las detracciones, se vieron más perjudicadas por el alza de la renta de la tierra que favorecidas por el aumento de precios y por las mayores posibilidades de comercialización de sus magros excedentes. Ahora bien, muchos de esos mismos pequeños campesinos, como el propio Yun reconoce, se beneficiaron del aumento de la demanda de trabajo ocasionado por el desarrollo de la cerealicultura, por el alza de la capacidad adquisitiva de parte del vecindario y por el crecimiento de la demanda de bienes y servicios generado por la intensificación del comercio. Consiguientemente, la mayor conexión de los mercados de granos contribuyó a una cierta movilización de la fuerza de trabajo de la comarca, fenómeno de gran trascendencia para el crecimiento de economías, como la de Tierra de Campos, en las que el grado de subempleo de los activos era elevado ${ }^{21}$.

¿Hubiera sido mejor para la mayor parte de terracampinos que las «sacas» de cereales no hubiesen aumentado en el siglo xvin? Probablemente, no. Los campesinos acomodados, los asalariados y los campesinos con muy pocas tierras habrían salido peor librados. Por su parte, los precios de los granos no habrian aumentado mucho menos debido al creciente déficit general de oferta y al menor alza de la producción agraria comarcal. Por tanto, los demandantes "netos" de cereales no habrían obtenido unas ventajas tan decisivas. Además, chabría quedado en ese caso la comarca mejor dispuesta para el desarrollo capitalista? En definitiva, la mayor integración de los mercados debió tener un efecto positivo sobre la economía de Tierra de Campos - nótese que, tras las reflexiones de Bartolomé Yun-, he sustituido el «muy favorable» por el «efecto neto positivo»-. No obstante, esta valoración podría modificarse si se demuestra la viabilidad bistórica de otro modelo de crecimiento económico comarcal en la segunda mitad del siglo xviII.

Bartolomé Yun realiza una lectura sesgada e incompleta de la segunda de mis «dudas y discrepancias» ${ }^{22}$. En ella quería resaltar que aquél no ha otorgado suficientemente atención a la «otra cara» del compromiso entre Carlos I y la aristocracia durante el conflicto comunero: las renuncias de la Monarquía y sus secuelas. Esta tuvo que admitir la no recuperación de las

It Jaume Torras (1982), p. 28.

${ }^{22}$ Revista de Historia Económica, año VI, núm. 3 (otoño 1988), pp. 749.750; Bartolomé Yun (1989), p. 475. 
rentas reales anteriormente enajenadas, lo que, habida cuenta de la agresiva y costosa política exterior, acabaría dificultando el desarrollo del Estado absoluto y propiciando importantes cambios económicos y sociales. ¿Era posible construir un aparato de Estado con capacidad operativa en todo el territorio de la Corona de Castilla cuando buena parte del producto de los tributos regios iba a parar a bolsillos privados y cuando la Hacienda registraba crónicos y crecientes déficits? Me parece que no. Y ello implicaba, entre otras cuestiones, que la Monarquía tenía que delegar la gestión y la recaudación tributaria a los ayuntamientos; es más, éstos, controlados en la mayor parte del territorio castellano por unas oligarquías cada vez más poderosas - Yun, al fijarse preferentemente en el caso de Tierra de Campos, ha tendido, a mi juicio, a sobrevalorar el papel de la comunidad aldeana-, fueron disponiendo de creciente margen de maniobra en materia fiscal a medida que la situación de la Hacienda se iba deteriorando. El modo en que se consolidó el «servicio de millones» revela la fuerza de las oligarquías y la debilidad del Estado a la hora de configurar el sistema impositivo: aquéllas fueron facultadas para modificar la naturaleza del nuevo tributo y para gestionar con mayor libertad el patrimonio territorial público ${ }^{23}$. Por tanto, la crisis estructural de la $\mathrm{Ha}$ cienda y la débil implantación territorial de la Administración Central ${ }^{24}$, propiciaron el encumbramiento político, económico y social de las oligarquías, lo que resultaría perjudicial para los intereses fiscales del Estado en el medio y largo plazo: el campesinado debió ser la principal víctima de la mayor desigualdad en la distribución de las cargas tributarias ${ }^{25}$. En suma, debe prestarse más atención a las oligarquías, tanto a las urbanas como a las rurales, a la hora de explicar el desarrollo del Antiguo Régimen en Castilla.

La no «desprivatización» de tercias y alcabalas también contribuyó, primero, a incrementar el endeudamiento de la Monarquía y, más tarde, a acelerar la escalada fiscal y a obligar a aquélla a enajenar jurisdicciones, rentas, derechos, cargos y tierras. La fuerte demanda de capitales por parte del Estado hubo de encarecer y restringir la financiación al sector privado; además, los hombres de negocios, que en la primera mitad del siglo xvi solían diversificar bastante sus inversiones ${ }^{26}$, tendieron a alejarse de las actividades manufac-

${ }^{23}$ Enrique Llopis (1986), pp. 29-31.

24 No es extraño que el gran desarrollo de la burocracia cortesana coincidiera con la escasa presencia de la Administración Central en las provincias de Castilla durante los Austrias: la Monarquía Hispánica colocaba un elevado porcentaje de sus recutsos humanos y financieros al servicio de la política exterior.

${ }_{25}$ Angel García Sanz, en una conferencia pronunciada el 16 de enero del presente año €n el Instituto de Estudios Fiscales, afirmó que algunos de los principales tributos, como los millones, se repartían con arreglo a un criterio demográfico, lo que resultaba muy perjudicial para las zonas rurales; además, las «derramas» solían realizarse de una manera arbitraria en función de los intereses de quienes controlaban los concejos de los pueblos.

${ }^{26}$ Véanse, por ejemplo, los patrimonios mobiliarios e inmobiliarios de los «mercaderes 
tureras y mercantiles a medida que el horizonte económico se fue ensombreciendo y que el Estado les ofreció vías de ascenso social y la posibilidad de adquirir activos financieros de elevada seguridad y de aceptable rentabilidad ${ }^{27}$.

Por su parte, las ventas de jurisdicciones, rentas, derechos, cargos y tierras resultarían perjudiciales para la mayor parte de las economías campesinas. De modo que el Estado estaba contribuyendo con estas actuaciones a minar la base productiva de Castilla ${ }^{28}$, lo que resultaría dañino para los propios intereses fiscales de aquél, sobre todo a medio y largo plazo.

La extracción centralizada del excedente cobró gran importancia en Castilla, pero conviene tener en cuenta que el asalto de la nobleza a la fiscalidad regia se había producido en el siglo xv; es decir, antes del desarrollo del Estado absoluto. Esto significa que los Reyes Católicos iniciaron el proceso de centralización política con un «espacio fiscal» reducido debido a las enajenaciones de rentas que se habían producido en el período de los Trastamara. Por ello, y por la ambiciosa y cara política exterior, el no ensanchamiento del «espacio fiscal» regio acabaría dificultando el pleno desarrollo del Estado absoluto y contribuyendo al fortalecimiento económico y político de las oligarquias y a la creciente debilidad de los campesinos y de la burguesía mercantil y manufacturera ${ }^{29}$. Por tanto, el compromiso al que llegaron la Monarquía y la aristocracia durante el conflicto comunero no fue ajeno a las carencias y peculiaridades del absolutismo castellano.

Además de examinar la extracción centralizada del excedente, sería aconsejable que no minusvaloremos otros procedimientos empleados por los grupos dominantes, nobles y no nobles, para apuntalar y mejorar sus economías: la sustitución de contratos y enfitéuticos por arrendamientos a corto plazo durante los siglos XV y xvi - con la consiguiente elevación de la renta y la

hacedores de paños» de Segovia en las primeras décadas del siglo xvi [Angel García Sanz (1987), pp. 65-79].

${ }^{27}$ Me parece un hecho significativo que la burguesía urbana abandone casi completamente la industria y reduzca su participación en los tráficos para concentrar sus inversiones en activos financieros, sobre todo cuando la mayoría de sus fondos se destinaban a la financiación del gasto público -que solía tener unos efectos expansivos limitados sobre la economía castellana, habida cuenta de que buena parte de las compras y de los pagos se efectuaban en el extranjero- y a la de los déficits de la aristocracia y los municipios. Considero, pues, que la división que realizo entre activos reales y financieros no es artificial.

${ }_{28}$ Angel García Sanz (1989), pp. 192-235.

27 En los núcleos urbanos, la escalada fiscal se instrumentó fundamentalmente a través de gravámenes sobre el consumo. Estos provocaron bruscas elevaciones de los precios de venta al público, lo que hubo de afectar a determinadas producciones y tráficos - vino, vinagre, aceite y manufacturas-. En Valladolid, por. ejemplo, dichos gravámenes representaron a veces porcentajes superiores al 40 por 100 del precio de venta al público [Adriano Gutiérrez Alonso (1989), pp. 159-161]. Es obvio que tal modo de repartir las nuevas cargas tributarias tuvo que ser un duro golpe para la burguesía mercantil e industrial de las ciudades castellanas. 
pérdida de derechos por parte de los usufructuarios-, las usurpaciones de baldíos y comunales y los acotamientos y adehesamientos. Quizá uno de los rasgos más característicos del "modelo castellano» lo constituya la simultaneidad y efectividad de las dos vías de extracción del excedente: la «centralizada» y la «descentralizada». La elevada participación de la nobleza en la fiscalidad regia _en el momento de iniciarse el proceso de centralización política- y, sobre todo, los grandes compromisos de gasto de la Monarquía Hispánica en otros territorios europeos, impidieron que la «vía centralizada» pudiese ser suficiente para saciar las necesidades y proyectos expansivos de los grupos dominantes. Por ello, el Estado hubo de consentir que éstos detrajeran directamente recursos a los campesinos a través de los cercamientos - ¿qué son, si no, la constitución de nuevas dehesas en los siglos XVI y XvII?y de la privatización de la propiedad o del usufructo de importantes bienes y derechos comunales.

En Tierra de Campos es muy probable que la vía «descentralizada» haya tenido una importancia secundaria, pero no todo el territorio de la Corona de Castilla estaba tan poblado, colonizado y "aristocratizado». En las extensas zonas de débil poblamiento de la parte meridional de la Meseta, los grupos dominantes, nobleza, grandes instituciones eclesiásticas y oligarquía, ya en el siglo XVII, parecen especialmente interesados en afianzar y ampliar sus derechos de propiedad sobre la tierra y en reducir los aprovechamientos comunales a fin de poder explotar en exclusiva o arrendar durante todo el año sus fincas - también para obtener mano de obra barata y/o mayores precios por los productos comercializados-. De modo que las futuras investigaciones no deberían, a mi juicio, partir del supuesto de la escasa relevancia de la vía «descentralizada» en el desarrollo de la Castilla moderna. Quizá las diferencias con respecto al caso francés alcancen un calibre parecido a las semejanzas. En cualquier caso, resulta incuestionable que la aportación de Yun nos ha permitido descubrir el importante papel del Estado absoluto en la distribución del ingreso entre los diferentes grupos sociales.

Para terminar, quisiera agradecer a Bartolomé Yun la deferencia que tuvo al remitirme su comentario a mi reseña bastante antes de que fuera publicado por la Revista de Historia Económica. Este intercambio de ideas, espero que provechoso, no va a afectar a nuestra amistad ni, desde luego, al respeto y admiración intelectual que siento por el autor de «Sobre la transición al capitalismo en Castillaw. 


\section{BIBLIOGRAFIA}

ANES, Gonzalo (1970): Las crisis agrarias en la España moderna, Madrid.

Box, G. E. P., y Jenkins, G. M. (1970): Time Series Analysis, Forecasting and Control, San Francisco.

Castro, Concepción de (1987): El pan de Madrid. El abasto de las ciudades españolas del Antiguo Régimen, Madrid.

EsCrivá, José Luis, y Llopis, Enrique (1987): «La integración del mercado triguero en la Castilla la Vieja-León del Antiguo Régimen: avance y estancamiento», Hacienda $P \dot{u}$ blica Española, núms. 108-109.

García Sanz, Angel (1977): Desarrollo y crisis del Antiguo Régimen en Castilla la Vieja. Economia y sociedad en tierras de Segovia, 1500-1814, Madrid.

- (1987): «Mercaderes hacedores de paños en Segovia en la época de Carlos V: Organización del proceso productivo y estructura del capital industrial», Hacienda Pública Es. pañola, núms. 108-109.

- (1989): «El sector agrario durante el siglo XVIr: depresión y reajustes», en José María Jover Zamora (dir.), Historia de España. Tomo XXIII: La crisis del siglo XVII. La Población. La Economia. La Sociedad, Madrid.

Gutiérrez Alonso, Adriano (1989): Estudio sobre la decadencia de Castilla. La ciudad de Valladolid en el siglo XVII, Valladolid.

LLOPIS, Enrique (1986): “El agro castellano en el siglo xvir: ¿depresión o "reajustes y readaptaciones"?", Revista de Historia Económica, año IV, núm. 1.

Maravall, Agustín, y Bentolila, Samuel (1984): Una medida de volatilidad de series temporales con una aplicación al control monetario en España, Madrid.

TORRAS, Jaume (1982): «La economía aragonesa en la transición al capitalismo. Un ensayo», en J. Torras, C. Forcadell y E. Fernández Clemente, Tres estudios de Historia Económica de Aragón, Zaragoza.

YUN, Bartolomé (1987): Sobre la transición al capitalismo en Castilla. Economía y Sociedad en Tierra de Campos (1500-1830), Salamanca.

- (1989): «De molinos a gigantes (A propósito de los comentarios de E. Llopis a "Sobre la transición al capitalismo en Castilla. Economía y Sociedad en Tierra de Campos, 1500-1830")», Revista de Historia Económica, año VII, núm. 2. 